\title{
Tracer Study Alumni: Upaya Pengembangan Prodi Bimbingan Konseling Universitas Negeri Makassar
}

\author{
Muhammad Ilham Bakhtiar, Suciani Latif \\ Program Studi Bimbingan dan Konseling, Fakultas Ilmu Pendidikan, Universitas Negeri Makassar, \\ Jl. Tamalate No. 1, Makassar, Sulawesi Selatan, Indonesia 90222 \\ Email: ilham_konseling@yahoo.com
}

Artikel diterima: 28 November 2016; direvisi 17 Januari 2017; disetujui 10 Februari 2017

\begin{abstract}
The aim of research to determine: (1) the profile of alumni student guidance and counseling; (2) a waiting period of alumni guidance and counseling; (3) the relevance of courses to the needs of the labor market; (4) the alumni users. This study is a qualitative research using descriptive survey method. The analysis conducted by the percentage and using three stages of data reduction, data presentation and conclusions. The results of this study through the instrument tracer study provides an overview achievement graduate GPA average of $78 \%$ or between 2.75 to 3.50 and there are $22 \%$ or 3.50 to 4.00 cum laude. The study period of Prodi Guidance and Counseling alumni is fairly fast 3.5-year study period, there were $13 \%$ and $68 \%$ of alumni completed the study precisely in the time period in 4 years. Similarly, waiting period to get their first job is very quick, the longest is 5 months with a percentage of $88 \%$. The job mostly occupied by the alumni is as a Guidance and Counseling Teacher (66\%). Users suggest competence enhancement of graduates in the field of foreign languages, especially English, skills or personal development skills, and mastery of technology needs to be developed.
\end{abstract}

Keywords: tracking; alumni; prodi guidance counseling

\begin{abstract}
Abstrak: Tujuan penelitian untuk mengetahui: (1) profil alumni mahasiswa bimbingan dan konseling; (2) masa tunggu alumni bimbingan dan konseling; (3) relevansi program studi dengan kebutuhan pasar kerja; (4) tanggapan pengguna alumni. Penelitian bersifat deskriptif kualitatif menggunakan metode survei. Analisis yang dilakukan dengan persentase dan menggunakan 3 tahapan yaitu reduksi data, penyajian data dan pengambilan kesimpulan. Hasil Penelitian yaitu penelusuran melalui instrumen tracer study memberikan gambaran pencapaian IPK lulusan rata-rata $78 \%$ atau di antara 2,75-3,50 dan terdapat $22 \%$ cum laude atau 3,50-4,00. Masa studi alumni Prodi Bimbingan dan Konseling terbilang cepat yaitu masa studi 3,5 tahun terdapat $13 \%$ serta $68 \%$ alumni menyelesaikan studi dengan tepat pada masa waktu yaitu 4 tahun. Demikian halnya masa tunggu mendapat pekerjaan pertama sangat cepat yaitu paling lama 5 bulan dengan persentase $88 \%$. Pekerjaan yang paling banyak ditempati oleh alumni adalah Guru Bimbingan dan Konseling dengan data 66\%. Pengguna menyarankan peningkatan kompetensi alumni dalam bidang bahasa asing khususnya bahasa inggris, kecakapan atau keterampilan pengembangan diri, serta penguasaan teknologi perlu lebih dikembangkan.
\end{abstract}

Kata kunci: pelacakan; alumni; prodi bimbingan konseling

Program studi adalah rumpun ilmu/ kesatuan kegiatan pendidikan dan pembelajaran yang memiliki kurikulum dan metode pembelajaran tertentu dalam satu jenis pendidikan akademik, pendidikan profesi, dan/ atau pendidikan vokasi dalam lingkungan UNM (Statuta UNM, 2015). Program studi Bimbingan Konseling sebagai unsur akademik di perguruan tinggi sadar akan fungsi dan tujuannya

Cara mengutip: Bakhtiar, M. I., \& Latif, S. (2017). Tracer Study Alumni: Upaya Pengembangan Prodi Bimbingan Konseling Universitas Negeri Makassar. Jurnal Kajian Bimbingan dan Konseling, 2(1), 32-40. Diambil dari http:// journal2.um.ac.id/index.php/jkbk/article/view/463 
yaitu: (1) menyiapkan tenaga konselor/ Guru pembimbing yang profesional sebagai pelaksana dan pengembang program bimbingan konseling di sekolah yang mencakup bidang bimbingan pribadi, sosial, belajar, karier, dan; (2) menyiapkan tenaga ahli/ pakar dalam bidang bimbingan dan konseling sebagai pengajar, peneliti dan pengabdi dalam bidang bimbingan dan konseling di perguruan tinggi (Renstra Prodi BK, 2015). Paradigma baru sistem Pendidikan Nasional mengarah pada antisipasi terhadap perkembangan di masa depan, termasuk di dalamnya hal-hal yang berkaitan dengan otonomi pendidikan. Oleh karena itu perlu dipersiapkan sistem pendidikan yang dapat menangani penyelenggaraan desentralisasi pendidikan.

Program studi berkualitas yang memiliki keunggulan kompetitif, akan mendorong peningkatan produktivitas dan efisiensi sehingga dapat menjadi instrumen bagi berlangsungnya proses transformasi di berbagai bidang kehidupan. Program Studi Bimbingan Konseling terus berupaya mengembangkan dan meningkatkan kualitas pendidikan, salah satunya adalah meningkatkan kualitas alumninya di berbagai sektor baik dari segi pembelajaran dan perbaikan kurikulum yang sesuai kebutuhan lapangan kerja

Alumni UNM merupakan seseorang yang telah menyelesaikan pendidikan di UNM (Statuta, 2015). Alumni program studi bimbingan konseling telah tersebar dari berbagai daerah, yang hingga saat ini alumni bimbingan konseling telah mencapai 413 orang. Data mahasiswa dan alumni mahasiswa program studi bimbingan dan konseling mulai tahun 2013 hingga tahun 2016 disajikan pada tabel 1.

Besarnya alumni program studi pada perguruan tinggi harus mampu berkiprah dalam pembangunan sesuai dengan pendidikannya atau bidang keahlian, dapat dilakukan dengan penelusuran terhadap lulusannya (Tracer Study). Hasil penelusuran alumni dapat digunakan oleh program studi untuk mengetahui keberhasilan proses pendidikan yang telah dilakukan terhadap anak didiknya.

Tracer study adalah studi pelacakan jejak lulusan/alumni yang dilakukan antara 1-3 tahun setelah lulus dan bertujuan untuk mengetahui outcome pendidikan dalam bentuk transisi dari dunia pendidikan tinggi ke dunia kerja, output pendidikan yaitu penilaian diri terhadap penguasaan dan pemerolehan kompetensi, proses pendidikan berupa evaluasi proses pembelajaran dan kontribusi pendidikan tinggi terhadap pemerolehan kompetensi serta input pendidikan berupa penggalian lebih lanjut terhadap informasi sosiobiografis lulusan (Dikti, 2011).

Pelacakan alumni perlu dilakukan agar setiap perguruan tinggi khususnya program studi dapat mengevaluasi seberapa besar lulusannya dapat terserap di dunia kerja sesuai dengan bidang ilmu yang ditekuninya di bangku kuliah, berapa lama waktu tunggu lulusan mendapat pekerjaan pertama setelah lulus, berapa besar gaji pertama lulusan, bahkan alumni dapat memberikan saran-saran yang dapat digunakan untuk perbaikan kurikulum perguruan tingginya.

Tujuan dari kegiatan pelacakan alumni atau tracer study adalah mengumpulkan informasi dan masukan yang relevan dari lulusan terkait dengan "learning and working experience" yang dialami oleh lulusan guna pengembangan Perguruan Tinggi. Tujuan utama dari kegiatan tracer study adalah untuk mengetahui/ mengidentifikasi kualitas lulusan di dunia kerja, sedangkan tujuan khusus tracer study adalah: (1) mengidentifikasi profil kompetensi dan keterampilan lulusan; (2) mengetahui relevansi dari pelaksanaan kurikulum yang telah diterapkan di perguruan tinggi dengan kebutuhan pasar tenaga kerja dan pengembangan professional di dalam kompetensi jurusan; (3) untuk mengevaluasi hubungan dari kurikulum dan studi di jurusan sebagai pengembangan keilmuan; (4) sebagai kontribusi dalam proses akreditasi jurusan (Schomburg, 2003). Tujuan tracer study adalah untuk perencanaan program, pembuatan keputusan, pengembangan profesional, perbaikan program, akuntabilitas dan akreditasi (Halasz \& Behm, 1982). Selain itu Pucel (1979) mengkategorikan tracer study menjadi 4 tujuan yaitu untuk mengetahui: (1) sejarah karier alumni; (2) status karier/ pekerjaan sekarang; (3) penilaian alumni terhadap program pendidikan atas dasar pengelaman kerja mereka; dan (4) evaluasi oleh pemberi kerja atau sejawat. Dari pendapat tersebut menggambarkan bahwa 
Tabel 1 Mahasiswa dan Alumni Program Studi Bimbingan dan Konseling

\begin{tabular}{cccc}
\hline No & Tahun Ajaran & Mahasiswa & Alumni \\
\hline 1 & 2013 & 109 & 106 \\
2 & 2014 & 90 & 83 \\
3 & 2015 & 68 & 73 \\
4 & 2016 & 75 & 30 \\
\hline & Total & $\mathbf{3 4 2}$ & $\mathbf{2 9 2}$ \\
\hline
\end{tabular}

Sumber data: BAAK UNM 2016

kegiatan surver alumni atau tracer study sangatlah penting demi untuk mengembangan program studi, mulai dari menetapkan profil program studi, menetapkan kompetensi alumni dan memberikan data kesesuaian pasar kerja dengan kurikulum yang dikembangkan pada program studi.

Untuk meningkatkan dan mengembangkan program studi dibutuhkan kegiatan pelacakan alumni program studi. Melalui penelitian ini maka akan dikaji tentang studi pelacakan alumni dalam rangka pengembangan program studi bimbingan dan konseling. Setelah mengkaji latar belakang di atas maka yang menjadi rumusan masalah dalam penelitian ini yaitu: (1) bagaimana profil alumni Bimbingan dan Konseling?; (2) bagaimana masa tunggu alumni Bimbingan dan Konseling?; (3) bagaimana relevansi program studi dengan kebutuhan pasar kerja?; (4) bagaimana tanggapan pengguna alumni terhadap alumni?

Penelitan ini bertujuan untuk mengetahui: (1) profil alumni Bimbingan dan konseling; (2) masa tunggu pekerjaan alumni Bimbingan dan Konseling; (3) relevansi program studi dengan kebutuhan pasar kerja; (4) tanggapan pengguna alumni.

\section{METODE}

Penelitian ini bersifat deskriktif kualitatif dengan menggunakan metode survei. Penelitian ini berupaya mengungkap pelacakan alumni Mahasiswa Program Studi Bimbingan dan Konseling Fakultas Ilmu Pendidikan Universitas Negeri Makassar. Populasi penelitian ini adalah seluruh alumni mahasiwa program studi Bimbingan dan Konseling dengan sampel penelitian alumni 4 (empat) tahun terakhir (lulus tahun 2012-2015) yang tersebar di berbagai daerah.

Alat pengumpulan data yang digunakan adalah angket. Angket digunakan untuk mendapatkan data pelacakan alumni mahasiswa Bimbingan dan Konseling yang terdiri dari bagian data pribadi alumni, tempat bekerja, saran dan masukan pengguna alumni. Teknik analisis data yang digunakan adalah analisis persentase (Hadi, 2007) dari tiap-tiap aspek dan analisis deskriktif dengan menghubung-hubungkan data-data yang diperoleh. Analisis deskriptif ini mencakup kegiatan: pengerjaan data; menatanya; mengkategorisasi; membuat pola; dan menguhubung-hubungkan data. Teknik analisis data yang digunakan dalam penelitian ini adalah sebagai berikut: reduksi data (data reduction); penyajian data (display data); pengambilan kesimpulan (verification)

\section{Tahap Pra-lapangan}

Pada tahap ini peneliti mengadakan survei pendahuluan. Selama proses ini peneliti mengadakan penjajakan lapangan (field study) terhadap subjek penelitian dan menyusun rancangan penelitian.

\section{Tahap Pekerjaan Lapangan}

Dalam tahap ini peneliti memasuki dan memahami setting penelitian dalam rangka pengumpulan data. Langkah-langkahnya adalah sebagai berikut: (1) membuat rute penelusuran berdasarkan sebaran daerah asal alumni; (2) melaksanakan penelusuran terhadap alumni yang terpilih secara acak dan lulus sampling; (3) kuisioner diberikan kepada alumni; (4) menyusun data lapangan sebagai bahan laporan; (5) evaluasi dan refleksi. 


\section{Tahap Analisis Data}

Peneliti melakukan serangkaian proses analisa data kuantitatif berupa angket sampai pada interpretasi data yang sudah diperoleh sebelumnya.

\section{Tahap Evaluasi dan Pelaporan}

Tahap ini merupakan tahap terakhir dan dilaksanakan setelah penelitian diuji.

\section{HASIL}

\section{Profil Alumni Mahasiswa Bimbingan dan Konseling}

Profil alumni mahasiswa bimbingan dan konseling dijelaskan dengan indikator: Indeks prestasi kumulatif, dan lama menyelesaikan studi.

\section{Hasil Perolehan Indeks Prestasi Kumulatif Mahasiswa}

Indeks prestasi kumulatif (IPK) dalam penelitian ini dibedakan menjadi tiga bagian yaitu: cum laude, sangat memuaskan, dan memuaskan. Hasil studi dokumen dalam menelusuri IPK alumni prodi bimbingan dan konseling untuk tahun ajaran 2012 sampai dengan tahun ajaran 2015 disajikan dalam tabel 2.

Tentang predikat IPK kelulusan mahasiswa Program Studi Bimbingan Konseling yang disajikan dalam gambar 1, dijelaskan bahwa untuk IPK kategori memuaskan 0\%, untuk IPK sangat memuaskan $78 \%$ dan cum laude sebanyak 22\%. Hal ini berarti bahwa pencapaian IPK lulusan alumni prodi BK sangat bagus karena sebagian besar hasilnya sangat memuaskan.

\section{Lama Menyelesaikan Studi}

Lama menyelesaikan masa studi dijelaskan dalam tabel 3. Di gambar 2 tentang masa studi alumni prodi bimbingan dan konseling dijelaskan bahwa untuk masa studi 3,5 tahun sebanyak $13 \%$, untuk masa studi 4 tahun sebanyak $68 \%$, untuk 5 tahun sebanyak $18 \%$ dan untuk 5 tahun ke atas sebanyak 1\%. Hal ini menunjukkan bahwa masa studi mahasiswa prodi BK sudah baik karena sebagian besar dapat menyelesaikan studi dengan tepat waktu atau selama 4 tahun.

\section{Masa Tunggu Pekerjaan}

Masa tunggu merupakan lamanya mahasiswa mendapatkan pekerjaan setelah dinyatakan selesai menempuh studi di perguruan tinggi hingga mendapatkan pekerjaan. Masa tunggu mendapat pekerjaan pertama disajikan dalam tabel 4. Pada gambar 3, diketahui bahwa masa tunggu alumni untuk mendapat pekerjaan pertama dibagi menjadi 4 (empat) kategori yaitu: untuk masa tunggu 1-5 bulan terdapat $88 \%$; untuk masa 5-12 bulan terdapat $7 \%$; untuk 12 bulan atau satu tahun terdapat $4 \%$; dan belum bekerja sebanyak $1 \%$. Dari grafik ini jelas bahwa alumni prodi BK sangat cepat mendapatkan pekerjaan setelah menyelesaikan studinya.

\section{Relevansi Program Studi Dengan Kebutuhan Pasar Kerja}

Dari alumni sebagai sampel penelitian, yang mengembalikan angket dan dapat dikonfirmasi yaitu sebanyak 74 orang. 49 orang atau $66 \%$ telah sesuai pekerjaan dan 16 orang atau $22 \%$ tidak sesuai dengan program studi dan ada 9 orang atau $12 \%$ belum memberikan konfirmasi kesesuaian dengan pekerjaannya. Jumlah persentase digambarkan pada gambar 4. Pada gambar 4 kesesuaian keilmuan dengan pekerjaan dijelaskan bahwa terdapat $66 \%$ kesesuaian alumni bekerja dengan keilmuannya, terdapat $22 \%$ tidak sesuai dan $12 \%$ belum memberikan respon kesesuaian. Hal ini membuktikan bahwa sebagian besar alumni prodi BK telah menempati pekerjaan sesuai dengan keilmuan yang dimiliki. 
Tabel 2 Predikat Kelulusan IPK Mahasiswa

\begin{tabular}{lcccc}
\hline Tahun & Jumlah & \multicolumn{3}{c}{ Predikat Kelulusan } \\
\cline { 3 - 5 } Lulus & Data & $\begin{array}{c}\text { Memuaskan } \\
<\mathbf{2 , 7 5}\end{array}$ & $\begin{array}{c}\text { Sangat } \\
\text { Memuaskan } \\
\mathbf{2 , 7 5 - 3 , 5 0}\end{array}$ & $\begin{array}{c}\text { Cumlaude } \\
\mathbf{7 3 , 5 0}\end{array}$ \\
\hline 2012 & 92 & 0 & 81 & 11 \\
2013 & 106 & 0 & 72 & 17 \\
2014 & 86 & 0 & 66 & 20 \\
2015 & 73 & 0 & 47 & 26 \\
\hline Total & $\mathbf{3 5 7}$ & $\mathbf{0}$ & $\mathbf{2 6 6}$ & $\mathbf{7 4}$ \\
\hline
\end{tabular}

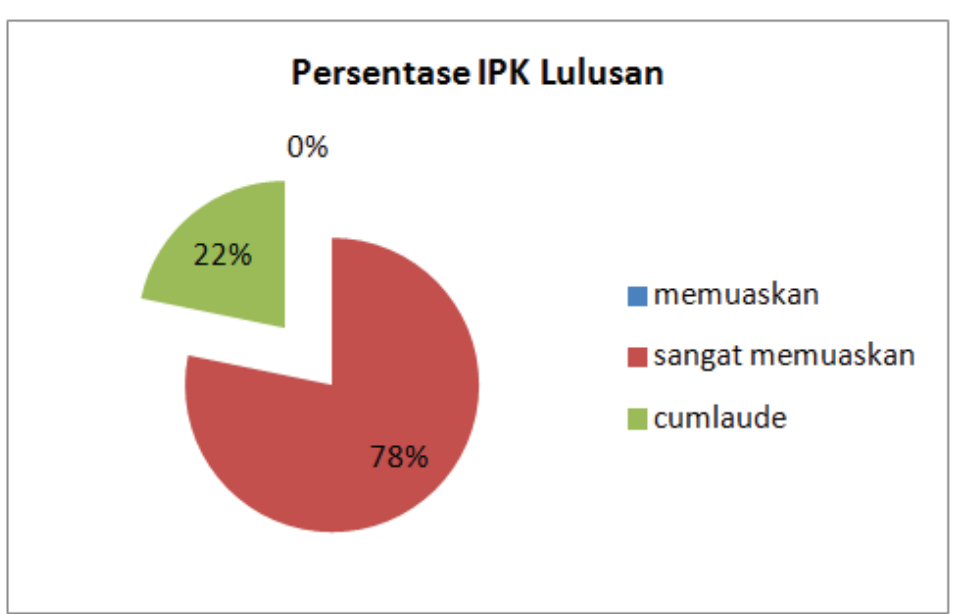

Gambar 1 Predikat IPK Kelulusan Mahasiswa

Tabel 3 Masa Studi Alumni

\begin{tabular}{|c|c|c|c|c|c|c|}
\hline \multirow[b]{2}{*}{ No } & \multirow[b]{2}{*}{$\begin{array}{l}\text { Tahun } \\
\text { Lulus }\end{array}$} & \multirow[b]{2}{*}{$\begin{array}{c}\text { Jumlah } \\
\text { Data }\end{array}$} & \multicolumn{4}{|c|}{ Lama Studi } \\
\hline & & & 3,5 tahun & 4 tahun & 5 tahun & $\begin{array}{l}5 \text { tahun } \\
\text { keatas }\end{array}$ \\
\hline 1 & 2012 & 92 & 10 & 60 & 19 & 3 \\
\hline 2 & 2013 & 106 & 13 & 82 & 9 & 2 \\
\hline 3 & 2014 & 86 & 12 & 54 & 20 & 0 \\
\hline 4 & 2015 & 73 & 10 & 45 & 18 & 0 \\
\hline \multicolumn{3}{|c|}{ Total } & 45 & 241 & 66 & 5 \\
\hline
\end{tabular}

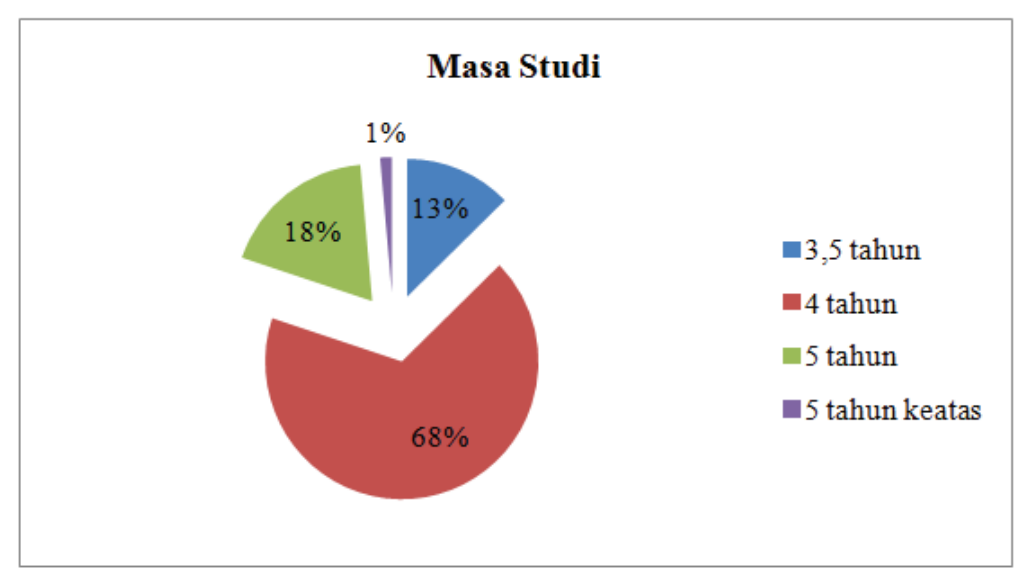

Gambar 2 Masa Studi Alumni Bimbingan Konseling 
Tabel 4 Masa Tunggu Mendapat Pekerjaan

\begin{tabular}{ccccccc}
\hline \multirow{2}{*}{ No } & Tahun & Jumlah & \multicolumn{5}{c}{ Masa Tunggu } \\
\cline { 4 - 7 } & Lulus & Data & $\mathbf{3 , 5}$ tahun & 4 tahun & $\mathbf{5}$ tahun & $\begin{array}{c}\text { 5 tahun } \\
\text { keatas }\end{array}$ \\
\hline 1 & 2012 & 92 & 81 & 5 & 4 & 2 \\
2 & 2013 & 106 & 93 & 13 & 0 & 0 \\
3 & 2014 & 86 & 82 & 4 & 0 & 0 \\
4 & 2015 & 73 & 50 & 10 & 12 & 1 \\
\hline & Total & & $\mathbf{3 0 6}$ & $\mathbf{2 4}$ & $\mathbf{1 6}$ & $\mathbf{3}$ \\
\hline
\end{tabular}

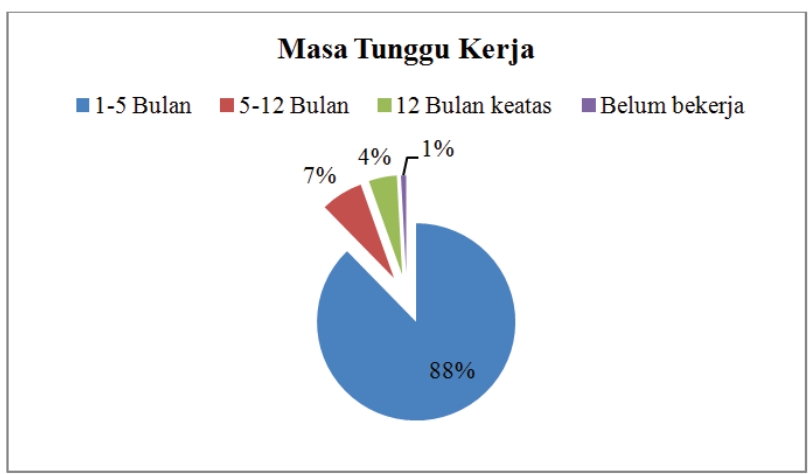

Gambar 3 Masa Tunggu Mendapat Pekerjaan Pertama

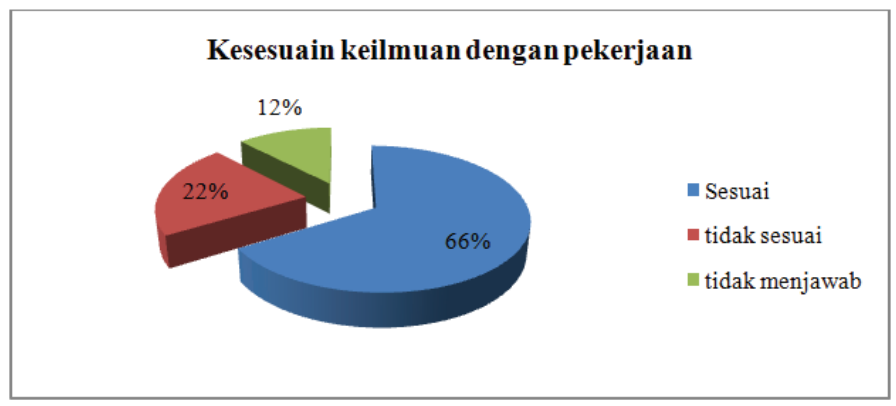

Gambar 4 Kesesuaian Keilmuan Dengan Pekerjaan

Tabel 5 Tanggapan Pihak Pengguna Alumni

\begin{tabular}{llcccc}
\hline & & \multicolumn{3}{c}{ Tanggapan Pihak Pengguna } \\
\cline { 3 - 6 } No & \multicolumn{1}{c}{ Jenis Kemampuan } & $\begin{array}{c}\text { Sangat } \\
\text { Baik } \\
\text { (dalam } \\
\text { persen) }\end{array}$ & $\begin{array}{c}\text { Baik } \\
\text { (dalam } \\
\text { persen) }\end{array}$ & $\begin{array}{c}\text { Cukup } \\
\text { (dalam } \\
\text { persen) }\end{array}$ & $\begin{array}{c}\text { Kurang } \\
\text { (dalam } \\
\text { persen) }\end{array}$ \\
\hline 1 & Integritas (etika dan moral) & 35,71 & 59,52 & 4,76 & 0,00 \\
2 & $\begin{array}{l}\text { Keahlian berdasarkan bidang ilmu } \\
\text { (profesionalisme) }\end{array}$ & 59,52 & 40,48 & 0,00 & 0,00 \\
3 & Bahasa Inggris & 7,14 & 23,81 & 47,62 & 21,43 \\
4 & Penggunaan teknologi informasi & 23,81 & 64,29 & 11,90 & 0,00 \\
5 & Komunikasi & 59,52 & 40,48 & 0,00 & 0,00 \\
6 & Kerjasama tim & 47,62 & 52,38 & 0,00 & 0,00 \\
7 & Pengembangan diri & 28,57 & 59,52 & 11,90 & 0,00 \\
\hline & $\quad$ Rata-rata & $\mathbf{3 7 , 4 1}$ & $\mathbf{4 8 , 6 4}$ & $\mathbf{1 0 , 8 8}$ & $\mathbf{3 , 0 6}$ \\
\hline
\end{tabular}




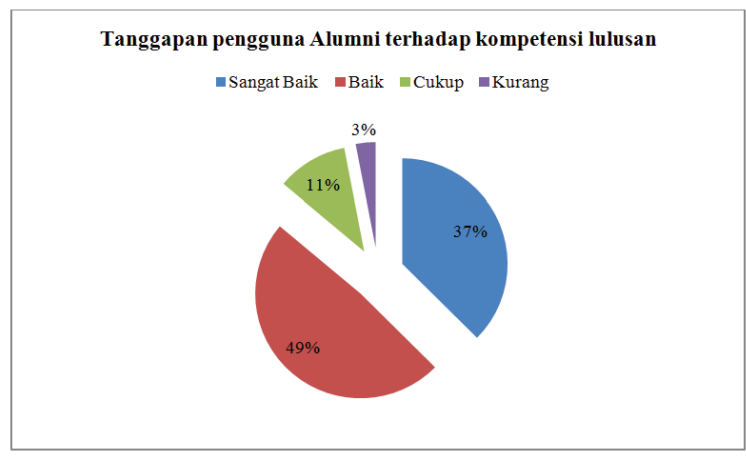

Gambar 5 Tanggapan Pengguna Alumni Terhadap Kompetensi Lulusan

\section{Tanggapan Pengguna Alumni Terhadap Kompetensi Lulusan}

Tanggapan pengguna dari stake holder, terdapat 20 instansi diantaranya sekolah memberikan hasil tanggapan sesuai angket yang telah disebar. Penilaian pengguna alumni terdiri dari integritas, keahlian berdasarkan ilmu, bahasa inggris/ asing, penggunan teknologi informasi, komunikasi, kerjasama tim dan pengembangan diri disajikan pada tabel 5. Pada gambar 5 menunjukkan bahwa sebagian besar pengguna alumni menyatakan bahwa kompetensi alumni prodi BK sudah sangat baik (terdapat 49\%), kemudian yang menyatakan baik sebanyak 37\%, 11\% sudah cukup dan masih terdapat 3\% kurang dari kompetensi alumni yang telah bekerja di instansi pemerintah dan swasta.

\section{PEMBAHASAN}

Pada aspek kemampuan kerja yang diukur dari tanggapan pengguna alumni, pengguna alumni di sekolah merasakan bahwa tingkat integritas, profesionalisme, penggunaan teknologi informasi, komunikasi, kerjasama tim, dan pengembangan diri sangat baik dan yang masih kurang adalah penguasaan bahasa asing. Hal tersebut menunjukkan bahwa alumni bimbingan konseling dapat mengaplikasikan kompetensi yang diperoleh selama perkuliahan dan menempatkan posisi dimana alumni bekerja serta meningkatkan kemampuan Bahasa Inggris.

Peran lulusan pada program studi bimbingan dan konseling tentunya harus mampu berkiprah dalam pembangunan sesuai dengan pendidikannya, dapat dilakukan dengan penelusuran terhadap lulusannya (tracer study). Hasil penelusuran alumni dapat digunakan oleh Program Studi Bimbingan dan Konseling untuk mengetahui keberhasilan proses pendidikan yang telah dilakukan terhadap anak didiknya. Tracer study adalah studi pelacakan jejak lulusan/alumni yang dilakukan antara 1-3 tahun setelah lulus dan bertujuan untuk mengetahui outcome pendidikan dalam bentuk transisi dari dunia pendidikan tinggi ke dunia kerja, output pendidikan yaitu penilaian diri terhadap penguasaan dan pemerolehan kompetensi, proses pendidikan berupa evaluasi proses pembelajaran dan kontribusi pendidikan tinggi terhadap pemerolehan kompetensi serta input pendidikan berupa penggalian lebih lanjut terhadap informasi sosiobiografis lulusan. (Dikti, 2011).

Hasil penelusuran melalui instrumen tracer study memberikan gambaran betapa besar peranan alumni dalam pembangunan program studi dari berbagai bidang akademik, baik dari segi pengembangan kurikulum, pembelajaran, kompetensi serta sarana dan prasarana yang ada.

IPK kelulusan mahasiswa program studi bimbingan konseling menggambarkan bahwa alumni telah mendapat predikat yang sangat baik sebanyak $78 \%$, kemudian terdapat pula mahasiswa yang cumlaude sebanyak $22 \%$. Hal ini berarti bahwa pencapaian IPK lulusan alumni prodi BK sangat bagus.

Masa studi alumni prodi bimbingan dan konseling dijelaskan bahwa terdapat studi yang cepat yaitu 3,5 tahun sebanyak 13\% alumni yang menyelesaikannya dengan cepat, serta alumni menyelesaikan studi dengan tepat waktu yaitu 4 tahun sebanyak $68 \%$. Hal tersebut menunjukkan bahwa masa studi mahasiswa prodi BK sudah baik karena rata-rata dapat menyelesaikan studi dengan tepat waktu atau selama 4 tahun dan mencapai prestasi cum laude. Dari pencapaian IPK 
dan masa studi mendukung kompetensi yang dimiliki mahasiswa bimbingan konseling sehingga pencapaian pekerjaan sangat cepat. Masa tunggu mendapat pekerjaan pertama sangat cepat karena hanya menunggu sampai 5 bulan sebanyak $88 \%$.

Dari data yang diperoleh, pekerjaan yang paling banyak ditempati oleh alumni adalah menjadi Guru Bimbingan dan Konseling, kemudian bekerja di perusahaan swasta dan menempati posisi HRD dan pegawai atau karyawan perusahaan. Hal ini sesuai dengan data bahwa $66 \%$ kesesuaian pekerjaan yang diperoleh alumni dengan keilmuan yang telah didapatkan saat menjadi mahasiswa. Namun beberapa tanggapan pengguna masih menyarankan peningkatan kompetensi kepada alumni khususnya bagi mahasiswa yang saat ini diantaranya bahasa asing atau bahasa inggris, kecakapan atau keterampilan pengembangan diri, serta penguasaan teknologi yang lebih dikembangkan.

Adapun berbagai usulan sebagai peningkatan pengembangan program studi bimbingan konseling FIP UNM melalui kegiatan ini, seperti dijelaskan oleh Meyer (1970) mereka mengklasifikasikan tracer study menjadi 3, yakni: (1) untuk memperbaiki pengajaran dan pembelajaran; (2) membantu alumni mencari kerja; (3) mengumpulkan informasi yang penting sehingga dapat untuk memperbaiki program. Maka perbaikan dapat dikelompokkan dalam bidang: kemampuan bahasa asing, dan kemampuan manajerial, serta kemampuan/kompetensi implementasi teknik-teknik konseling. Hal ini berarti masih terdapat kekurangan yang harus disempurnakan, utamanya menyangkut bidangbidang yang disarankan sebagaimana tersebut di atas, seperti kompetensi penguasaan bahasa asing atau inggris, yang perlu diberi porsi yang memadai karena lulusan prodi bimbingan konseling dalam pekerjaaan sudah menempati pos yang tepat namun belum bisa bersaing dengan perkembangan gloalisasi saat ini yang telah dituntut untuk menguasai bahasa asing dan teknologi, pengembangan diri dalam bidang soft skill dan hard skill karena alumni pada dasarnya telah memiliki IPK yang sangat baik dan memuaskan namun perlunya peningkatan kecakapan demi menunjang pekerjaan di lapangan. Peningkatan kurikulum juga perlu diperhatikan walaupaun lulusan telah mencapai rata lulusan tepat sesuai masa studinya namun kurikulum hendaknya disesuaikan dengan kebutuhan dilapangan seperti program matakuliah pengembangan kompetensi bidang karir, dan sosial. Peran ikatan alumni juga perlu di maksimalkan dalam menjadi fasilitator penempatan kerja alumni di lapangan. Perlunya meningkatkan hubungan lulusan dan almamater, karena apabila dilihat dari pengalaman institusi-institusi pendidikan terkenal, ikatan lulusan dan almamater yang kuat akan banyak membawa banyak manfaat kepada almamater seiring dengan diakuinya kiprah lulusan di masyarakat (Soemantri, 2010:4).

\section{SIMPULAN}

Dari pelaksanaan penelitian maka dapat disimpulkan: (1) profil lulusan mahasiswa bimbingan konseling yaitu IPK kelulusan mahasiswa program studi bimbingan konseling menggambarkan bahwa alumni telah mendapat predikat yang sangat baik sebanyak $78 \%$, kemudian terdapat pula mahasiswa yang cum laude sebanyak $22 \%$. Hal ini berarti bahwa pencapaian IPK lulusan alumni prodi BK sangat bagus; (2) masa studi alumni prodi bimbingan dan konseling dijelaskan bahwa terdapat studi yang cepat yaitu masa studi 3,5 tahun sebanyak $13 \%$, serta alumni menyelesaikan studi dengan tepat waktu yaitu 4 tahun sebanyak $68 \%$. Masa tunggu untuk mendapat pekerjaan pertama sangat cepat karena hanya menunggu selama 5 bulan sebanyak $88 \%$; (3) tanggapan pengguna alumni menjelaskan bahwa kompetensi alumni prodi BK sudah sangat baik sebanyak $49 \%$, kemudian pada kategori baik sebanyak 37\%, 11\% sudah cukup dan masih terdapat 3\% kurang dari kompetensi alumni yang telah berkerja di instansi pemerintah dan swasta. Beberapa tanggapan dari pengguna masih menyarankan peningkatan kompetensi kepada alumni khususnya bagi mahasiswa yang saat ini, diantaranya bahasa asing atau bahasa inggris, kecakapan atau keterampilan pengembangan diri, serta penguasaan teknologi yang lebih dikembangkan; (4) dari data yang diperoleh, pekerjaan yang paling banyak ditempati oleh alumni adalah menjadi Guru Bimbingan dan Konseling, kemudian bekerja di perusahaan swasta seperti HRD dan pegawai atau karyawan perusahaan. Hal ini berarti bahwa $66 \%$ alumni memiliki kesesuaian pekerjaan dengan keilmuan yang telah didapatkan saat 
menjadi mahasiswa; (5) tanggapan pengguna masih menyarankan peningkatan kompetensi kepada alumni khususnya bagi mahasiswa diantaranya bahasa asing atau bahasa inggris, kecakapan atau keterampilan pengembangan diri, serta penguasaan teknologi yang lebih dikembangkan.

Dari hasil penelitian disarankan kepada pimpinan program studi agar menjadi masukan dalam mengembangan kurikulum ke arah yang berbasis KKNI. Kemudian kepada calon peneliti agar penelitian ini dijadikan bahan kajian untuk melakukan penelitan yang lebih luas lagi.

\section{DAFTAR RUJUKAN}

Dirjen Dikti. (2011). NOMOR 49/DIKTI/Kep/2011 tentang pedoman akreditasi.

Halasz, I., \& Behm, K. (1982). Evaluating Vocational Education Programs. A Handbook for Corrections Educators. Research and Development Series No. 227. National Center for Research in Vocational Education, National Center Publications, Box F, 1960 Kenny Rd., Columbus, OH 43210.

Hadi. (2007). Metodologi Penelitian Pendidikan. Bandung: Pustaka Setia.

Meyer, W. G. (1970). Coordination in cooperative vocational education. Ohio: Charles. E. Marril Publishing company.

Pucel, D. J. (1972). The Wilms Study: Analysis of Methodology. Journal of Vocational Education Research, 1(1), 3-10, Win 76.

Renstra BK. (2015). Bimbingan dan Konseling.

Schomburg, H. (2003). Handbook for Graduate Tracer Studies. Centre for Research on Higher Education and Work University of Kassel. First published. Bonn, Germany: Deutsche Gesellschaft für Technische Zusammenarbeit (GTZ) GmbH.

Statuta.(2015). Universitas Negeri Makassar.

Soemantri, dkk. (2010). Kajian Relevansi Lulusan Jurusan Pendidikan Geografi Uny Tahun 20052009. Yogyakarta: FISE UNY 